\title{
New Selective Estrogen Receptor Modulators (SERMs) in Development
}

\author{
Stuart L. Silverman
}

Published online: 7 July 2010

(C) The Author(s) 2010. This article is published with open access at Springerlink.com

\begin{abstract}
Selective estrogen receptor modulators (SERMs) or estrogen agonists/antagonists have shown promise in osteoporosis in that they have the potential to reduce the risk of fracture, and also reduce the risk of breast cancer. SERMs maybe classified according to their core structure, which is typically a variation of the 17 beta-estradiol template and subclassified according to the side chain at the helix 12 affector region. The best known are the triphenylethylenes such as tamoxifen, used in the management of breast cancer. However, the clinical application of this class of SERMs has been limited due to endometrial stimulation. A second class is the benzothiophenes such as raloxifene and arzoxifene, which have skeletal benefit with little, if any, uterine stimulation. Indole-based SERMs such as bazedoxifene have a 2-phenyl ring system that serves as a core binding unit. Other classes include benzopyrans and naphthalenes (eg, lasofoxifene). In this review article, I will discuss raloxifene and three new SERMs - arzoxifene, bazedoxifene, and lasofoxifene - that have been recently studied. I will discuss their effect on bone, breast, and the cardiovascular system, as well as on safety.
\end{abstract}

Keywords SERMs · Osteoporosis · Arzoxifene ·

Bazedoxifene $\cdot$ Lasofoxifene

\section{Clinical Trial Acronyms}

GENERATIONS Global Investigation to Determine

Efficacy of Arzoxifene on At-risk

Postmenopasal Patients

\section{S. L. Silverman $(\triangle)$}

Clinical Professor of Medicine and Rheumatology,

Cedars-Sinai/UCLA,

8641 Wilshire Boulevard, Suite 301,

Beverly Hills, CA 90211, USA

e-mail: stuarts@omcresearch.org
MORE
Multiple Outcomes of Raloxifene
Evaluation
PEARL
Postmenopausal Evaluation and
Risk-Reduction with Lasofoxifene

\section{Introduction}

We now have a diverse menu of osteoporosis therapies including both antiresorptive and anabolic therapies. Antiresorptive therapies include bisphosphonates, calcitonin, and selective estrogen receptor modulators (SERMs), also called estrogen agonists/antagonists. The first SERM, raloxifene, was shown to reduce risk of vertebral fracture but not nonvertebral fracture with an important extraskeletal effect of reducing invasive breast cancer [1]. The potential to reduce fracture risk and breast cancer risk has led to further development of new SERMs with the hope that a SERM would also reduce nonvertebral fracture risk. In this article, I will discuss newer SERMS in late development: arzoxifene, lasofoxifene, and bazedoxifene.

\section{Effect on Bone}

Raloxifene

The MORE trial was an international, randomized, placebo-controlled 3-year trial of the safety and efficacy of raloxifene in 7,705 postmenopausal women who met the World Health Organization criteria for having osteoporosis [1]. Women were randomized to 60 or $120 \mathrm{mg}$ of raloxifene or placebo. Raloxifene reduced the risk of vertebral fracture compared with placebo (hazard 
ratio $[\mathrm{HR}], 0.7 ; 95 \% \mathrm{CI}, 0.5-0.8)$. Raloxifene did not reduce the risk of nonvertebral fracture. Raloxifene reduced markers of bone turnover by $26 \%$ to $31 \%$ for osteocalcin and by $32 \%$ to $34 \%$ for CTX-I. Raloxifene increased bone mineral density (BMD) by $2.6 \%$ to $2.7 \%$ at the lumbar spine and $2.1 \%$ to $2.4 \%$ at the femoral neck.

\section{Lasofoxifene}

The PEARL trial was an international, randomized, placebo-controlled 5-year trial of the safety and efficacy of lasofoxifene [2••] in which 8,556 postmenopausal women with osteoporosis in the femoral neck or spine were randomized to a placebo, low-dose $(0.25 \mathrm{mg})$ or high-dose lasofoxifene $(0.5 \mathrm{mg})$. Lasofoxifene at a dose of $0.5 \mathrm{mg} / \mathrm{d}$ compared with placebo was associated with reduced risk of vertebral fracture (HR, $0.58 ; 95 \% \mathrm{CI}$, $0.47-0.70$ ). Lasofoxifene was associated with reduced risk of nonvertebral fracture (HR, 0.76; 95\% CI, 0.64-0.91). Lasofoxifene improved BMD over 5 years in the lumbar spine by $3.1 \%$ at a dose of $0.5 \mathrm{mg}$ compared with the placebo group. Lasofoxifene increased BMD in the femoral neck by $2.9 \%$ and by $2.7 \%$ in the total hip.

\section{Bazedoxifene}

The bazedoxifene study was a 5-year international, doubleblind, randomized, placebo- and active-controlled trial of 7,492 women at 206 sites [3••]. Results of the first 3 years have been published and will be discussed here. The results of the 5 years have been presented but not published. Treatments included 20 or $40 \mathrm{mg}$ of bazedoxifene, $60 \mathrm{mg}$ of raloxifene, or placebo taken once daily. Inclusion criteria included women 55 to 85 years of age with osteoporosis as defined by a BMD of -2.5 to -4.0 or at least one radiographic-confirmed vertebral fracture with a BMD greater than -4.0 . Bazedoxifene reduced the risk of new vertebral fractures at both doses: $20 \mathrm{mg}(\mathrm{HR}, 0.58 ; 95 \% \mathrm{CI}$, $0.38-0.89$ ), and $40 \mathrm{mg}$ (HR, 0.63; 95\% CI, 0.42-0.96); compared with raloxifene, $60 \mathrm{mg}$ (HR, 0.58; 95\% CI, 0.380.89 ), compared with placebo. For nonvertebral fracture, no significant differences in nonvertebral fracture rate were seen in the general study population. However, in a post hoc analysis of 1,772 women who were at higher risk for fracture (eg, a femoral neck T-score $<-3.0$ and/or had at least one moderate or severe vertebral fracture or more than one mild vertebral fracture at baseline), bazedoxifene at $20 \mathrm{mg}$ reduced the nonvertebral risk by $50 \%$ versus placebo $(P=0.02)$. In addition, the risk of nonvertebral fracture risk was $44 \%$ lower than with raloxifene in the same group $(P=0.05)$.

\section{Arzoxifene}

Arzoxifene was studied in the GENERATIONS, a multicenter, placebo-controlled, double-blind 5-year randomized trial of 9,354 women with osteoporosis $(n=5,252)$ or low bone mass $(n=4,102)$ [4]. Arzoxifene reduced the risk of vertebral fracture up to 3 years in patients with osteoporosis (HR, $0.59 ; 95 \% \mathrm{CI}, 0.45-0.77 ; P<0.01$ ) but not nonvertebral fracture (HR, $0.92 ; 95 \% \mathrm{CI}, 0.71-1.19 ; P=0.071)$. Results were similar in participants with low bone mass. At 12 months, in participants with low bone mass, arzoxifene reduced bone markers such as CTX by $32 \%$, was associated with a $42.1 \%$ reduction in CTX, and $33.5 \%$ reduction in P1NP in 12 months, with 3-year increases in BMD of $2.6 \%$ in the total hip, $2.8 \%$ in femoral neck, and $2.9 \%$ at lumbar spine. In the absence of nonvertebral efficacy, arzoxifene has been withdrawn from further clinical development.

\section{Relationship of SERMs Efficacy to Fracture Risk}

One of the questions asked of all agents is the relationship of fracture risk to efficacy. The assumption has been made that patients with higher fracture risk would have greater efficacy with an osteoporosis agent. The effects of the SERMs have not been consistent. Raloxifene, as reported by McCloskey et al. [5], which had significantly decreased risk of all clinical fractures and morphometric fractures in the MORE trial, had no significant interaction of efficacy with 10-year fracture risk assessment tool (FRAX) probability. In the case of morphometric vertebral fractures, efficacy decreased with increasing age. At the 90th percentile of age, vertebral fracture risk was reduced by $31 \%$ independent of FRAX probabilities. In contrast, at younger ages, efficacy was higher and increased further still with decreasing fracture probability. In contrast, the same investigators found that reductions in fracture risk with bazedoxifene were greater as the probability of fracture risk increased [6].

\section{Cardiovascular Effects}

Selective estrogen receptor modulators offer the promise of reducing the burden of coronary artery disease (CAD) based on the promise of lipids and markers of inflammation being reduced.

Raloxifene failed to lower the risk of CAD in postmenopausal osteoporotic women but doubled the risk of venous thromboembolism. The risk of CAD was lowered in a subgroup of patients at high risk. In a large, randomized, controlled trial with $\mathrm{CAD}$ as the primary end point, raloxifene failed to significantly reduce $\mathrm{CAD}$ while 
significantly increasing the fatal stroke of venous thromboembolism [7].

In the primary trial, bazedoxifene also increased the risk of venous thromboembolism [3・•]. In the PEARL trial, lasofoxifene reduced the risk of heart disease events, as well as the risk of stroke, whereas the risk of deep vein thrombosis remained in line with other SERMs $[2 \bullet \bullet]$.

Reports of the effect of arzoxifene on cardiovascular events have not been published.

\section{Effects on Breast Cancer}

Raloxifene has been noted to reduce the risk of invasive breast cancer [8]. In the GENERATIONS trial, arzoxifene reduced the risk of invasive breast cancer by $56 \%$ after 4 years of treatment $(P=0.002)$. Lasofoxifene reduced the risk of estrogen receptor-positive breast cancer, 0.3 versus 1.7 cases per 1,000 person-years (HR, $0.19 ; 95 \%$ CI, $0.07-0.56)$.

\section{Effects on Uterus}

Of the newer SERMs in development, lasofoxifene has been shown to reduce fractures and decrease the risk of breast cancer but has been associated with increased incidence of vaginal bleeding and endometrial thickening and endometrial polyps [9]. However, lasofoxifene has also shown beneficial effects in the vaginal epithelium [9]. Bazedoxifene has had no adverse effects on endometrium or breast [10].

\section{Conclusions}

Further investigation into new SERMS is warranted to more clearly define the bone and gynecologic safety and potential effects on both breast cancer and cardiovascular risk. It is clear that SERMS differ in their efficacy and safety profiles.

Disclosure Dr. Stuart L. Silverman has been a consultant for Warner Chilcott, Roche Pharmaceuticals, Roche Diagnostics, Novartis, Pfizer, and Eli Lily and Co. He has received grants from Eli Lily and Co. and Alliance for Better Bone Health. He has also received honoraria from Eli Lily and Co., Roche Pharmaceuticals, and Pfizer.

Open Access This article is distributed under the terms of the Creative Commons Attribution Noncommercial License which permits any noncommercial use, distribution, and reproduction in any medium, provided the original author(s) and source are credited.

\section{References}

Papers of particular interest, published recently, have been highlighted as:

•- Of major importance

1. Ettinger B, Black DM, Mitlak BH, et al.: Reduction in vertebral fracture risk in postmenopausal women with osteoporosis with raloxifene: results from a 3 year randomized clinical trial. Multiple Outcomes of Raloxifene Evaluation (MORE) Investigators. JAMA 1999, 282:637-645.

2. • Cummings SR, Ensrud K, Delmas PD, et al.: Lasofoxifene in postmenopausal women with osteoporosis. N Engl J Med 2010, 362:686-696. This is the treatment trial for lasofoxifene.

3. • Silverman SL, Christiansen C, Genant HK, et al.: Efficacy of bazedoxifene in reducing new vertebral fracture risk in postmenopausal women with osteoporosis: results from a 3 year randomized, placebo and active controlled clinical trial. J Bone Miner Res 2008, 23:1923-1934. This is the treatment trial for bazedoxifene.

4. Reginster JY, McClung MR, Cox D, et al.: The effects of arzoxifene on fracture incidence in postmenopausal women with osteoporosis or with low bone mass [abstract OC 30]. Osteoporos Int 2010, 21(Suppl 1):S23.

5. McCloskey E, Kanis J, Johansson A: FRAX and the effect of raloxifene on vertebral and non-vertebral fracture. Osteoporos Int 2010, 21(Suppl 1):S7-S24.

6. Kanis JA, Johansson H, Oden A, et al.: Bazedoxifene reduces vertebral and clinical fractures in postmenopausal women at high risk assessed with FRAX. Bone 2009, 44:1049-1054.

7. de Villiers TJ: Clinical issues regarding cardiovascular disease and selective estrogen receptor modulators in postmenopausal women. Climacteric 2009, 12(Suppl 1):108-111.

8. Nelson HD, Fu R, Griffin JC, et al.: Systematic review: comparative effectiveness of medications to reduce risk for primary breast cancer. Ann Intern Med 2009, 151:703-715.

9. Pinkerton JV, Goldstein SR: Endometrial safety: a key hurdle for selective estrogen receptor modulators in development. Menopause 2010, 17:642-653.

10. Miller PD, Chines AA, Christiansen C, et al.: Effects of bazedoxifene on BMD and bone turnover in postmenopausal women: $2 \mathrm{yr}$ results of a randomized, double blind, placebo and active controlled study. J Bone Miner Res 2008, 23:525535 . 